\title{
Inter-linkage among some physico-chemical and biological factors in the tropical mangrove estuary
}

\begin{abstract}
The interaction between abiotic and biotic parameters in an ecosystem usually shows health and functioning of the system. Thus, some physico-chemical parameters, phytoplankton abundance, chlorophyll a and primary production of the mangrove estuary in Sarawak, Malaysia were extensively investigated from January 2013 to December 2013 in order to establish the inter-linkage among them. The Pearson correlation coefficient revealed a significant relation between atmospheric and water temperatures $(r=0.692)$. Similarly, surface water temperature showed a significant positive correlation with salinity $(r=0.744)$, TDS $(r=0.708)$ and conductivity $(r=0.776)$. The light extinction coefficient (LEC, K) changed negatively in relation to TDS $(r=-0.623)$, conductivity $(r=-0.644)$ and surface water temperature $(r=-0.766)$. Ammonium showed a negative correlation with rainfall $(r=-0.620)$ but a positive correlation with salinity $(\mathrm{r}=0.600)$. The biological variable such as phytoplankton abundance was found to be positively correlated with chlorophyll a $(\mathrm{r}=$ $0.692)$, ammonium $(r=0.645)$ and silica $(r=0.644)$ and negatively with rainfall $(r=-0.644)$. The canonical correspondence analysis revealed a strong positive correlation between environmental parameters and phytoplankton species. The analysis of variance disclosed significant seasonal differences in salinity, water temperature, TDS, conductivity, LEC, ammonium and chlorophyll a.
\end{abstract}

Keyword: Chlorophyll a; Mangrove estuary; Physico-chemical parameters; Phytoplankton; Primary production 